\title{
DESENVOLVIMENTO MORAL NA CIBERCULTURA
}

\author{
Wagner Roberto Dias Nascimento ${ }^{1}$; https://orcid.org/0000-0001-6058-5803
}

Ana Cristina Salviato-Silva²; https://orcid.org/0000-0002-1014-0643

Betânia Alves Veiga Dell’ Agli³; https://orcid.org/0000-0002-8805-2838

\begin{abstract}
Resumo
A maneira como as tecnologias digitais de informação e comunicação são discutidas e ensinadas em ambiente escolar podem não incluir de maneira sistemática a discussão sobre o impacto no comportamento ético. Privilegia-se apresentálas como ferramenta de estudos, engajamento ou entretenimento, porém sua utilização em idade cada vez mais precoce apresenta a cibercultura para um indivíduo em desenvolvimento moral, com implicações ainda pouco exploradas uma vez que é fenômeno recente. O objetivo deste artigo é analisar reações diante de situações de cunho ético e moral no uso de tecnologias digitais de informação e comunicação (TDIC) por universitários que foram expostos à internet em idade de desenvolvimento moral. De abordagem quantitativa, este artigo inclui uma breve explanação sobre teorias de desenvolvimento moral e apresenta os resultados de um estudo de campo com 308 participantes, em situações tais como pirataria, plágio e cyberbullying. Foi possível identificar divergência no comportamento em razão da mídia empregada. Também se destaca a importância de as instituições manterem canais apropriados para acolhimento de problemas relacionados ao uso inadequado da internet, e indica a educomunicação como possibilidade para superação desse desafio e progresso do desenvolvimento humano local e global.
\end{abstract}

Palavras-chave: Internet; Moral; Educação; Desenvolvimento humano; Educomunicação

\section{Moral Development in Cyberculture}

\begin{abstract}
The way digital information and communication technologies are discussed and taught in a school environment may not systematically include the debate about the impact on ethical behavior. The preference is to present them as a tool for studies, engagement or entertainment, but its use at an earlier age presents cyberculture to a person in moral development, with implications still little explored since it is a recent phenomenon. The objective of this article is to analyze reactions to ethical and moral situations in the use of digital information and communication technologies by college students who were exposed to the internet at the age of moral development. From a quantitative approach, this paper includes a brief explanation of moral development theories and presents the results of a study with 308 participants in situations such as piracy, plagiarism and cyberbullying. It was possible to identify divergence in behavior due to the media used. It also highlights the importance of institutions maintaining appropriate networks to address problems related to the inadequate use of the Internet, and indicates educommunication to overcome this challenge and progress of local and global human development.
\end{abstract}

Keywords: Internet; Moral; Education; Human development; Educommunication.

\section{Desarrollo Moral en la Cibercultura}

\section{Resumen}

La forma en que se discuten y enseñan las tecnologías de la información y la comunicación digitales en un entorno escolar puede no incluir sistemáticamente la discusión sobre el impacto en el comportamiento ético. Se prefiere presentarlos como una herramienta para estudios, participación o entretenimiento, pero su uso a una edad cada vez más temprana,

1 Centro Universitário das Faculdades Associadas de Ensino - UNIFAE - São João da Boa Vista - SP - Brasil; wagnernnascimento@gmail.com

2 Centro Universitário das Faculdades Associadas de Ensino - UNIFAE - São João da Boa Vista - SP - Brasil; anasalviato@uol.com.br

3 Centro Universitário das Faculdades Associadas de Ensino - UNIFAE - São João da Boa Vista - SP - Brasil; betania@fae.br 
presentar la cibercultura para un individuo en desarrollo moral tiene implicaciones todavia poco exploradas ya que es un fenómeno reciente. El objetivo de este artículo es analizar reacciones ante situaciones de carácter ético y moral en el uso de tecnologías digitales de información y comunicación (TDIC) por universitarios que fueron expuestos a internet en edad de desarrollo moral. De natureza cuantitativa, este artículo incluye una breve explicación sobre teorías de desarrollo moral y presenta los resultados de un estudio de campo con 308 participantes, en situaciones tales como piratería, plagio y ciberacoso. Fue posible identificar la divergencia en el comportamiento debido a los medios utilizados. También destaca la importancia de que las instituciones mantengan canales adecuados para acojer los problemas relacionados con el uso inadecuado de Internet e indica que a educomunicación como una posibilidad para superación de este desafío y el progreso del desarrollo humano local y global.

Palabras clave: Internet; Moral; Educación; Desarrollo humano Educomunicación.

\section{Introdução}

A noção de moral acompanha a ideia de viver em sociedade. Ideias de uma moral universal e independente do lugar ou contexto formaram a base para o conceito de imperativo categórico, apresentado por Immanuel Kant em 1786. Para esse pesquisador, os indivíduos deveriam "agir com todos como todos gostariam de serem tratados" (Kant, 2007).

Em divergência a esse caráter universalista, a partir do final do século XIX a cultura e história do homem começaram a ter maior ênfase nas pesquisas sobre moralidade, adotaram um caráter científico e se afastaram dos conceitos empregados pelas religiões e biologia (Gert \& Gert, 2016; La Taille, 2006; Srivastava, Dhingra, Bhardwaj \& Srivastava, 2013).

Em 1922, Emile Durkhein propõe o conceito de fato social, em que o indivíduo é moldado pelo grupo do qual participa e este exerce coerção em suas atitudes. Para esse autor, a educação moral deveria ser laica, pois comportar-se bem significaria obedecer conscientemente (Silva, Silva \& Montoya, 2014).

Nesse mesmo ano, Jean Piaget publica seus estudos no livro "O juízo moral da criança" (Piaget, 1994). A inteligência é necessária, porém insuficiente para o desenvolvimento moral, pois no amadurecimento da criança, prática e cognição evoluem e o indivíduo avança nos níveis de desenvolvimento moral. Inicia-se com a anomia, passa pela heteronomia entre seis e dez anos e finalmente atinge a autonomia, à medida que acomoda conscientemente no seu modo de agir valores universais de respeito e colaboração (Piaget, 1994). Para esse autor, a moral é uma síntese entre a afetividade e a inteligência. A autoridade natural dos pais em estabelecer regras a serem seguidas pelas crianças com o tempo é substituída pela transmissão de princípios e valores dos quais tais preceitos se originaram.
Em 1983, Eliot Turiel propõe a Teoria dos Domínios Moral e Convencional (Turiel, 1983), em que o contexto é importante para se analisar as convenções sobre o modo de agir (domínio convencional), enquanto o domínio moral independe do lugar ou dos sujeitos, e está ligado às emoções primárias de justiça, equidade e evitar danos às pessoas (Turiel, 2012).

Com a introdução da internet comercial no Brasil em 1995, uma geração denominada "nativos digitais" cresceu imersa em seus recursos durante o processo de amadurecimento (Prensky, 2001). Na atualidade, os meios eletrônicos de comunicação correspondem à sensibilidade dos jovens, visto que são dinâmicos, rápidos, "tocam primeiro o sentimento, depois a razão" (Moran, 1993, p. 21). A sensibilidade moral está ligada à dimensão intelectual e à capacidade cognitiva (La Taille, 2006), que em vários aspectos foi ampliada, exteriorizada e modificada pelo ciberespaço (Levy, 1999).

De acordo com a Teoria dos Fundamentos Morais, proposta por Jonathan Haidt, em 2007, existem cinco fundamentos (cuidado, equidade, lealdade, respeito e pureza) sobre os quais as culturas variam no grau em que constroem suas virtudes (Haidt \& Graham, 2007). Cinco anos depois, o mesmo autor aperfeiçoou sua teoria e incluiu a liberdade como sexto fundamento moral, sobre a qual comenta que estão desenvolvendo múltiplas formas de medição (Haidt, 2012). Esse pesquisador sugere que tais fundamentos poderiam ser a chave para se entender inclusive as grandes diferenças entre liberais e conservadores.

Os fundamentos morais podem ser comparados às estruturas primárias sobre as quais são construídos os princípios, valores e regras de comportamento, que atuam em conjunto e moldam os tipos de ordens morais que podem ser desenvolvidas mais facilmente em uma cultura (Graham, 2012). 
O ambiente virtual possui uma cultura própria denominada cibercultura, na qual crianças e adolescentes são expostos durante seu processo de desenvolvimento moral. Nela há recursos e convenções sociais, "uma necessidade de instantaneidade que se opõe às práticas culturais tradicionais” (Santaella, 2013, p. 25).

Neste artigo serão apresentados resultados acerca da investigação sobre as reações diante de situações de cunho ético e moral no uso de tecnologias digitais de informação e comunicação (TDIC) por universitários que foram expostos à internet quando ainda eram crianças ou adolescentes.

\section{Método}

Trata-se de um estudo de campo, não experimental, transversal, descritivo e de abordagem quantitativa (Sampieri, Collado \& Lucio, 2013).

O tamanho da amostra foi calculado a partir da população de 900 estudantes, margem de erro $5 \%$ e nível de confiança $95 \%$, o que resultou no tamanho da amostra de 269 participantes (Cochran, 2007).

A abordagem quantitativa foi adotada por permitir um número maior de participantes, com economia de tempo e custo quando comparados aos existentes nos métodos qualitativos para o mesmo número de voluntários (Creswell, 2007).

Para atender aos objetivos da pesquisa, foi utilizado como instrumento um questionário auto aplicado, elaborado pelos autores em formato eletrônico, acessível por meio de um link de internet.

A primeira parte do instrumento consistiu na apresentação da pesquisa e o Termo de Consentimento Livre e Esclarecido, que somente após aceite em participar habilitou a continuidade em responder.

A segunda parte do questionário solicitou alguns dados cadastrais, tais como idade e sexo, de modo que o anonimato permanecesse garantido. Em seguida, foram apresentadas assertivas sobre situações de cunho ético ou moral, em que o participante deveria apontar uma opção de resposta pré-determinada que melhor lhe agradasse.

\section{Participantes}

Foram convidados a participar do presente estudo discentes de um curso presencial de uma universidade pública brasileira.
Foi adotado como critério de inclusão estarem presentes no dia previsto para coleta, ou seja, o instrumento não foi disponibilizado para a mesma turma em nova oportunidade. O critério de exclusão correspondeu aos discentes com idade menor que dezoito anos ou com questionários que não foram preenchidos completamente.

\section{Procedimento}

A presente pesquisa foi autorizada pela direção da unidade e seguiu rigorosamente o protocolo aprovado pelo Comitê de Ética em Pesquisa com Seres Humanos (Brasil, 2012). Na sequência, por meio dos horários de aula disponíveis no site da instituição, identificaram-se os docentes responsáveis por disciplinas nos laboratórios de informática, que foram contatados e autorizaram um período em torno de quinze minutos, previamente agendado no início de suas aulas, para a aplicação do instrumento.

O pesquisador compareceu no início das aulas de catorze turmas, dos períodos noturno e integral, apresentou a pesquisa e forneceu o link para acesso ao instrumento.

Não houve contato adicional com o pesquisador durante o preenchimento. O tempo médio para respondê-lo foi de 14 minutos e, após a coleta, o link foi desativado para prevenir novos acessos.

Os dados coletados no instrumento de coleta disponível na internet foram exportados para uma planilha eletrônica e analisados estatisticamente por meio da ferramenta Action Stat (Equipe Estatcamp, 2014).

\section{Resultados e discussão}

Trezentos e onze discentes aceitaram participar e responderam completamente a pesquisa, entre eles três mulheres com idade 17 anos, que atenderam ao critério de exclusão e suas respostas foram excluídas, de maneira que os resultados se apoiam em 308 participantes, distribuídos em 172 homens (56\%) e 136 mulheres (44\%).

Os dados coletados permitem observar que a idade média dos alunos é 20,6 anos e desvio-padrão 2,76 . Os nativos digitais são $82 \%$ da amostra; essa proporção apresenta uma tendência de crescimento a cada semestre com o ingresso de mais calouros. No ensino superior, está ocorrendo a transição entre imigrantes e nativos digitais, caracterizando uma oportunidade 
para as instituições se beneficiarem desse momento para troca de experiências entre eles, promoção da integração e redução da desigualdade digital (Freeman, Adams Becker, \& Hall, 2015; Jones, Ramanau, Cross, \& Healing, 2010).

A investigação acerca da idade da primeira utilização da internet revelou que para $26 \%$ isso aconteceu até seus 8 anos, $62 \%$ entre 9 e 12 anos e $12 \%$ com treze anos ou mais. Foi calculado o tempo desde que isso ocorreu, resultando na mediana 10 anos, com amplitude de 17 anos, indicando grande variação. Dentro da mesma geração, há diferentes níveis de letramento digital e experiências de uso da tecnologia (Ricoy, Feliz \& Couto, 2013; Roberto, Fidalgo \& Buckingham, 2015).

Associam-se a esses dados o cenário que havia no Brasil há uma década, quando a exposição à internet era menor. No ano 2004, 6,3 milhões de domicílios utilizavam a internet e, em 2014, o número registrado foi 36,8 milhões (ampliação de 584\%), dentre os quais 8,6 milhões a acessam somente por tablets, smartphones e TV digital (IBGE, 2016), ou seja, dispositivos muitas vezes utilizados para entretenimento por crianças e que "alteram nossa identidade individual, coletiva e interferem em nossos afetos" (Schwartz, 2013, p. 240).

Inteligência e afetividade concorrem para a formação moral do indivíduo (La Taille, 2006), sendo que as crianças imergem em um ambiente virtual que possui cultura própria (Levy, 1999) ainda no período de seu desenvolvimento moral (Piaget, 1994). Isso sugere que a internet influencia o desenvolvimento moral do indivíduo.

A exploração sobre eventuais diferenças com relação ao sexo, revela que as mulheres foram expostas ligeiramente mais cedo do que os homens, com valores tri-média $\mathrm{H}=9,73$ e $\mathrm{M}=10,19$, em que foi adotado o percentual $10 \%$ nesse cálculo para prevenir a eventual influência de outliers. No entanto, o método KruskalWallis não apontou evidência estatística para descartar a hipótese de que sejam iguais.

Meninas conversam mais ao celular, enquanto meninos o utilizam mais para jogos (Fitton, Ahmedani, Harold \& Shifflet, 2013). Importante destacar que crianças mais jovens têm maiores dificuldades em reconhecer as intenções em postagens on-line (Talwar, Gomez-Garibello \& Shariff, 2014), exigindo maior atuação dos pais no aconselhamento, porém muitas vezes estes não são reconhecidos pelos filhos como referência em assuntos relacionados às tecnologias digitais de informação e comunicação.

Muitos pais e educadores cresceram quando a internet era pouco utilizada e atualmente precisam orientar as crianças sobre perigos que não existiam na época, como, por exemplo, violência mediada por computador, fácil exposição à pornografia, cyberbullying, transmissão de fotos ou mensagens de conteúdo sexual pela internet ou celular (sexting) e vício em internet (Emilia, Nobre, \& Bretan 2012; Ma, Keung Ma, \& Ma, 2011).

Os participantes da pesquisa foram questionados se consideram questões éticas quando utilizam tecnologia; nesse quesito as mulheres apresentaram um desempenho superior aos homens, com média entre "muitas vezes" e "sempre". Foi realizado teste estatístico para a hipótese de diferenciação das respostas entre os sexos; o método Kruskal-Wallis confirma a hipótese de diferenciação entre homens e mulheres, com p-valor ajustado de 0,001614. Em relação a essa tendência, Lau (2014) identificou que os homens assumem comportamento de maior risco, praticam mais pirataria e plágio acadêmico.

Foi investigado o comportamento dos estudantes no cenário de acesso indevido e antecipado ao conteúdo da prova nas mídias papel e tela, sem que ninguém mais soubesse. Para o grupo que respondeu que ao receber a prova em papel resolveria sozinho, foi questionado qual seria sua reação caso a prova fosse visualizada em tela. A alteração no cenário proposto ocorreu apenas na mídia empregada, uma vez que as demais condições, inclusive de anonimato, permaneceram inalteradas. Os resultados obtidos são apresentados na Tabela 1.

É possível observar que apenas $26 \%$ manteria a mesma conduta. Um comportamento tão antagônico sugere a existência de traços de heteronomia, pois a autonomia apresenta atitudes de cooperação e respeito fundamentadas em princípios e valores estáveis (Silva, Silva \& Montoya, 2014).

Flores (2013) encontrou evidências que nas decisões tomadas no ambiente on-line há grande tolerância com conduta não ética. Para esse autor, interações on-line podem favorecer uma desconexão entre o pensamento ético-moral e a ação, inclusive em relação a pessoas conhecidas e, mesmo que capazes de agir moralmente, não demonstram interesse em fazê-lo. 
Tabela 1

Variação da resposta "Resolveria sozinho" em papel ao alterar a mídia para tela

\begin{tabular}{lc}
\hline & $\%$ \\
\hline Fecharia imediatamente & 53 \\
Resolveria sozinho & 26 \\
Avisaria o professor & 16 \\
Olharia para se preparar melhor & 5 \\
Compartilharia com a turma & 0 \\
Resolveria com amigos mais próximos & 0 \\
Total & 100 \\
\hline
\end{tabular}

Fonte: dados da pesquisa

$\mathrm{O}$ acesso a tecnologias que facilitam a cópia, transmissão e compartilhamento de arquivos pode facilitar uma conduta de não observância de direitos autorais. No caso de programas de computador, recebe o nome de pirataria de software e em pesquisas escolares o nome de plágio acadêmico. Tais comportamentos "contribuem para a construção da identidade do indivíduo e na sua relação de estar e ser no coletivo" (Livingstone, 2014, p. 80).

Foram investigadas as reações em relação ao plágio e pirataria, com o argumento que essa atitude diminuiria o tempo gasto para realização da atividade. Para ambas assertivas, as opções de respostas eram idênticas. Os resultados ficaram distribuídos conforme Figura 1:

\begin{tabular}{|c|c|c|c|c|c|}
\hline & \multicolumn{5}{|c|}{ PLÁGIO } \\
\hline & A & B & C & D & Total \\
\hline A & $\mathbf{1 2} \%$ & $1 \%$ & 0 & $1 \%$ & $14 \%$ \\
\hline B & $\mathbf{3 6} \%$ & $\mathbf{4} \%$ & $\mathbf{1} \%$ & $\mathbf{3} \%$ & $\mathbf{4 4} \%$ \\
\hline C & $\mathbf{1 8 \%}$ & $1 \%$ & $2 \%$ & $5 \%$ & $26 \%$ \\
\hline D & $1 \%$ & \\
\hline D & $\mathbf{1 1} \%$ & 0 & 0 & $5 \%$ & $16 \%$ \\
\hline Total & $\mathbf{7 7} \%$ & $6 \%$ & $3 \%$ & $14 \%$ & $100 \%$ \\
\hline
\end{tabular}

Legenda: $A=$ acho errado e não faria; $B=$ acho errado, mas faria; $C=$ não vejo problemas; $\mathrm{D}=$ não vejo problemas, mas não faria

Figura 1. Julgamento e atitudes em relação ao plágio acadêmico e pirataria

Os resultados destacados evidenciam que a pirataria é algo amplamente aceito para consecução dos objetivos, apontado por $44 \%$ dos participantes. Em segundo lugar estão aqueles que sequer consideram problemas nessa prática, identificados no grupo "não vejo problemas", sugerindo insensibilidade moral para essa atitude, pois falta "capacidade de perceber as dimensões morais de certas ações ou situações nas quais estas não aparecem com evidência" (La Taille, 2006, p. 87).

Isso ocorre mesmo entre aqueles que não fariam plágio acadêmico, que foi rejeitado por $77 \%$ dos participantes.

$\mathrm{O}$ argumento relativo ao custo de aquisição do aplicativo pode ser descartado, uma vez que o plágio de obras acadêmicas em geral é gratuito e, no entanto foi pouquíssimo relatado.

No caso do software, os motivadores para evitar a pirataria são a noção de prejuízo ao fornecedor e principalmente a honestidade pessoal do consumidor (Casali \& Da Costa, 2014). A discussão sobre pirataria e legalidade é ampla, uma das razões é a fronteira entre o particular e público na internet, por vezes nebuloso. Por exemplo, empresas ignoram a privacidade e registram dados pessoais sem autorização e os comercializam para empresas de marketing dirigido (Benjamin, 2017; Prensky, 2006).

Para se explorar as reações diante de recebimento de conteúdo digital ofensivo e de forma continuada (ciberbullying), nesse cenário foi proposta uma lista com doze opções, baseadas no estudo de Orel et al. (2015), dentre as quais o participante poderia apontar até quatro delas. Os resultados estão representados na Tabela 2.

Os dados coletados indicam que os homens apontaram mais opções que as mulheres. Eles ignoram, vingam-se, contra-atacam e pedem ajuda da família mais do que as mulheres, enquanto estas buscam mais o diálogo com o agressor ou pedem ajuda. Essa diferença de comportamento entre os sexos também foi encontrada em estudantes suíços (Machmutow, 
Tabela 2

Reações ao ser alvo, de forma continuada, de conteúdo digital ofensivo

\begin{tabular}{lccc}
\hline & Mulheres & Homens & Total \\
\hline Afastar-se do agressor & 0 & 6 & 6 \\
Ameaçar denunciar & 15 & 8 & 23 \\
Bloquear o remetente & 104 & 119 & 223 \\
Denunciar & 115 & 125 & 240 \\
Ignorar & 33 & 60 & 93 \\
Pedir a outros que contra-ataquem & 7 & 16 & 23 \\
Pedir ajuda aos amigos & 24 & 47 \\
Pedir ajuda para administração & 65 & 23 & 126 \\
Pedir ajuda para família & 3 & 61 & 18 \\
Pedir ajuda para um(a) professor(a) & 36 & 15 & 69 \\
Pedir ao agressor para parar & 21 & 33 & 46 \\
Retaliar (vingar - se) & 3 & 25 & 18 \\
Total & 426 & 15 & 932 \\
\hline
\end{tabular}

Fonte: dados da pesquisa

Perren, Sticca \& Alsaker, 2012), o que pode sugerir que eventuais diferenças de cultura entre Brasil e Suíça não geraram mudanças significativas de atitude.

Independente do sexo, a maior incidência foi na opção denunciar, o que reforça a importância de as instituições manterem canais adequados para comunicação desse problema, disponíveis e com pessoal capacitado.

O desconforto causado por esse tipo de violência pode levar a dificuldades de concentração, percepção pelos alunos de falta de controle da turma por parte dos professores, dores (principalmente de cabeça e estômago), faltas, baixo desempenho escolar, evasão escolar, problemas econômicos e suicídio. Estima-se que, no mundo, a cada ano 246 milhões de crianças e adolescentes experimentem alguma forma de violência escolar (UNESCO, 2017).

O Programa Internacional de Avaliação de Estudantes (PISA) indica que no Brasil 17,5\% dos estudantes sofrem bullying pelo menos uma vez por mês e o desempenho escolar em ciências é $26 \%$ menor entre escolas com alta incidência dessa violência (OCDE, 2017). Reduzi-lo é socialmente, economicamente e academicamente vantajoso.

A legislação brasileira inclui o Programa de Combate à Intimidação Sistemática (Brasil, 2014b), que impõe aos estabelecimentos de ensino o dever de adotar medidas para conscientizar, prevenir, diagnosticar e combater o bullying. Também traz como objetivos orientar os responsáveis pelos agressores, pela vítima, docentes e equipe pedagógica, para promoção da cidadania e cultura de paz.

O estudo de campo também comparou os fundamentos morais relatados em relacionamento presencial e virtual; foram encontradas diferenças, conforme Figura 2.

Nos fundamentos que apresentaram maior e menor frequência nota-se estabilidade entre os dois cenários, enquanto a sensibilidade apresentou grande variação proporcional. No entanto, a hipótese de que o conjunto seja estatisticamente diferente foi descartada pelo método Kruskall-Wallis.

As redes sociais mediadas por computador tornaram-se populares, ao mesmo tempo que a moralidade torna possível a vida em sociedade, mas "na telecidade, os outros aparecem somente como objetos de gozo, sem que nenhum laço os prenda (podem ser eliminados da tela - e assim lançados para fora do mundo - quando pararem de divertir)" (Bauman, 1997, p. 204). Os resultados encontrados de que no ambiente virtual existe menor lealdade e maior liberdade parecem suportar a ideia desse autor.

O conceito de que o currículo escolar deve capacitar o uso de recursos das tecnologias digitais de informação e comunicação é importante, porém limitada. É necessário favorecer a formação de cidadãos digitais que reconheçam seus direitos, responsabilidades e contribuam para o desenvolvimento humano localmente e globalmente (ISTE, 2016; PNUD, 2001). 


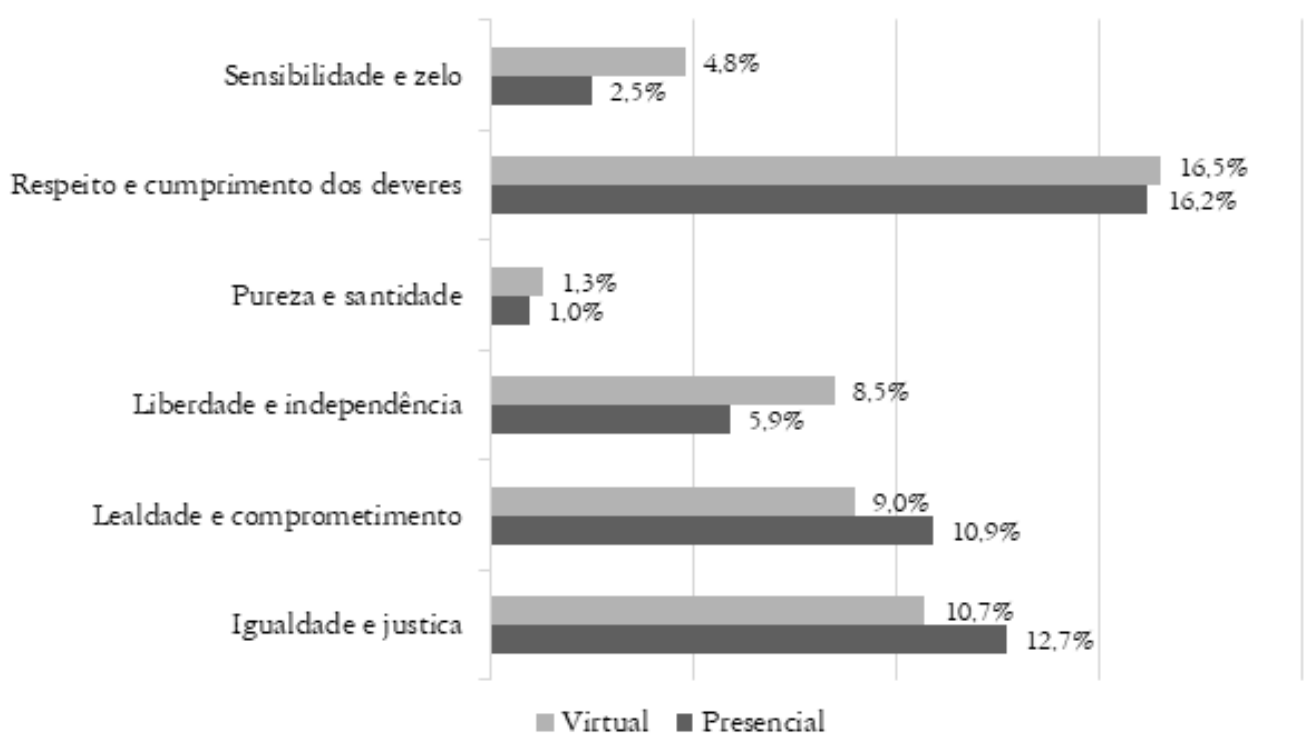

Figura 2. Fundamentos morais mais importantes em ambiente presencial e virtual

\section{Considerações finais}

A revisão da literatura e os resultados da pesquisa apontam que o desenvolvimento moral é influenciado pela cultura, e que a geração denominada nativos-digitais é adepta da cibercultura, de modo que as atitudes morais e éticas são influenciadas pelas tecnologias digitais de informação e comunicação.

A idade da primeira exposição a internet antecipa-se cada vez mais, ampliando no público infantil as oportunidades de educação e entretenimento, concorrente às ameaças ergonômicas, cyberbullying, sexting ou simplesmente isolamento social.

Os eventuais efeitos podem ser observados também na idade adulta; o grupo pesquisado apresentou variações no comportamento dependendo da mídia empregada.

A inclusão digital inclui educação sobre uso seguro, consciente e responsável da internet para o desenvolvimento da cidadania (Brasil, 2014a). A sinergia entre educação e comunicação, com vistas ao desenvolvimento da cidadania, pode se beneficiar dos conceitos e práticas de educomunicação (Soares, 2006).

$\mathrm{Na}$ educomunicação associa-se educação com as mídias, pelas mídias e para as mídias, empoderando o estudante em ações de autoração que, além de valorizar o conhecimento em tecnologias dos nativos digitais, favorecem a percepção do outro nas causas e efeitos das atitudes midiáticas, incluindo mais uma possibilidade de progresso do desenvolvimento humano por meio das tecnologias digitais de informação e comunicação.
Nessa abordagem o aluno produz narrativas ou jogos digitais, engaja-se socialmente e encontra possibilidades de aprender inclusive tecnologias digitais de informação e comunicação, na medida que as utiliza como um meio para atingir um objetivo maior. Para essa geração conectada, um programa de computador ou relato de experiência apoiado por TDIC tornam a aprendizagem mais significativa e efetiva (Valente, 1997, 2016).

Alinhar a educação à realidade dos jovens imersos em TDIC inclui mais uma possibilidade de progresso do desenvolvimento humano. Ações em ambiente virtual por definição não se restringem ao espaço geográfico em que foram praticadas, mas podem influenciar localmente ou globalmente.

Instituições de ensino de todos os níveis devem se preparar e, nesse contexto, estudos sobre moral auxiliam o entendimento sobre os fundamentos a partir do qual emanam as regras de conduta, pois será naqueles pilares que se encontrará a estabilidade necessária para tempos de modernidade líquida entre administradores, docentes e alunos.

Um dos pilares no qual se sustenta o compromisso assumido na Agenda 2030 (Unesco, 2015), de avançarmos no desenvolvimento humano sem deixar ninguém para trás, é a educação inclusiva e equitativa de qualidade para todas as pessoas. Em um mundo ciberdependente, isso certamente se beneficiará de ações que conjuguem o desenvolvimento em tecnologias digitais de informação e comunicação com autonomia moral de todos. 


\section{Referências}

Bauman, Z. (1997). Ética Pós-Moderna (J.R.Costa, trad.). São Paulo: Paulus. (Trabalho original publicado em 1993).

Benjamin, G. (2017). Privacy as a Cultural Phenomenon. Journal of Media Critiques, 3(10). https://doi.org/10.17349/ Jmc117204

Brasil. Resolução no 466, de 12 de dezembro de 2012 Estabelece diretrizes e normas envolvendo pesquisas com seres humanos (2012). Brasília-DF: Ministério da Saúde.

Brasil. Lei n ${ }^{\circ}$ 12.965, de 23 de abril de 2014 - Estabelece princípios, garantias, direitos e deveres para o uso da Internet no Brasil (2014). Brasília-DF.

Brasil. Lei no 13185 , de 06 de novembro de 2015 - institui o programa de combate a intimidação sistemática (bullying) (2014). Brasília-DF.

Casali, R. D. R. B., \& Da Costa, F. J. (2014). Uma análise dos impactos da estrutura de custos percebida sobre a predisposição à pirataria de software. REGE - Revista de Gestão, 21(2), 253-268. https://doi.org/10.5700/ rege 529.

Cochran, W. G. (2007). Sampling techniques. Wiley India Limited.

Creswell, J. W. (2007). Projeto de pesquisa: métodos qualitativo, quantitativo e misto. trad. Luciana de Oliveira da Rocha. (Trabalho original publicado em 2003).

Emilia, M., Nobre, A., \& Bretan, M. E. A. N. (2012). Violência sexual contra crianças e adolescentes mediada pela tecnologia da informação e comunicação: elementos para a prevenção vitimal. Tese de doutorado. Universidade de São Paulo, São Paulo. Recuperado de http://www. teses.usp.br/teses/disponiveis/2/2136/tde-22042013$111456 / \mathrm{publico} /$ tese_completa_maria_emilia_a_n bretan_fd_usp2012.pdf

Equipe Estatcamp. (2014). Software Action. São Carlos - SP, Brasil: Estatcamp- Consultoria em estatística e qualidade.

Fitton, V., Ahmedani, B., Harold, R., \& Shifflet, E. (2013). The Role of Technology on Young Adolescent Development: Implications for Policy, Research and Practice. Child and Adolescent Social Work Journal, 30(5), 399-413. https://doi.org/10.1007/s10560-013-0296-2

Flores, A., \& James, C. (2013). Morality and ethics behind the screen: Young people's perspectives on digital life. New Media E Society, 15(6), 834-852. https://doi. org/10.1177/1461444812462842
Freeman, A., Adams Becker, S., \& Hall, C. (2015). 2015 NMC Technology Outlook for Brazilian Universities: A Horizon Project Regional Report. Austin, Texas.

Gert, B., \& Gert, J. (2016). The Definition of Morality. Stanford Encyclopedia of Philosophy, Spring.

Graham, J. (2012). Running head: Moral Foundations Theory. New York.

Haidt, J., \& Graham, J (2007). When morality opposes justice: Conservatives have moral intuitions that liberals may not recognize. Social Justice Research, 20, (1), 98-116.

Haidt, J. (2012) The righteous mind: why good people are divided by politics and religion. New York, USA: Knopf Doubleday Publishing Group.

IBGE. (2016). Acesso à internet e à televisão e posse de telefone móvel celular para uso pessoal. Rio de Janeiro: IBGE.

ISTE. (2016). Standards for Students: transformative learning with technology. Arlington/USA. Recuperado de https://www.iste.org/standards/standards/for-students

Jones, C., Ramanau, R., Cross, S., \& Healing, G. (2010). Net generation or Digital Natives: Is there a distinct new generation entering university? Computers and Education, 54(3), 722-732. https://doi.org/10.1016/j. compedu.2009.09.022

Kant, I. (2007). Fundamentação da Metafísica dos Costumes (P. Quintela, trad.). Lisboa/Portugal: Edições 70. (Trabalho original publicado em 1785).

La Taille, Y. de. (2006). Moral e ética: dimensões intelectuais e afetivas. Porto Alegre: Artmed.

Lau, W. W. F., \& Yuen, A. H. K. (2014). Internet ethics of adolescents: Understanding demographic differences. Computers E Education, 72, 378-385. https://doi. org/10.1016/j.compedu.2013.12.006

Levy, P. (1999). Cibercultura (trad. C.I. Costa). São Paulo: Editora 34. (Trabalho original publicado em 1997).

Livingstone, S. (2014). Evidence-based recommendations for parents, teachers and policy makers: a view from Europe. ICT Kids Online Brazil 2013: Survey on Internet Use by Children in Brazil, 177-184. Retrieved from http:// www.cetic.br/publicacoes/2012/tic-kids-online-2012.pdf

Ma, H. K., Keung Ma, H., \& Ma, H. K. (2011). Internet Addiction and Antisocial Internet Behavior of Adolescents. TheScientificWorldJOURNAL, 11, $2187-$ 2196. https://doi.org/10.1100/2011/308631 
Machmutow, K., Perren, S., Sticca, F., \& Alsaker, F. D. (2012). Peer victimisation and depressive symptoms: Can specific coping strategies buffer the negative impact of cybervictimisation? Emotional and Behavioural Difficulties, 17(3-4), 403-420. https://doi.org/10.1080/13632752 .2012 .704310

Moran, J. M. (1993). Leitura dos meios de comunicação. São Paulo: Pancast.

OCDE. (2017). PISA 2015 Results (Volume III) Students' Well-Being. Paris, France: PISA. https://doi.org/http:// dx.doi.org/10.1787/9789264273856-en

Orel, A., Campbell, M., Wozencroft, K., Leong, E., \& Kimpton, M. (2015). Exploring university students' coping strategy intentions for cyberbullying. Journal of Interpersonal Violence, 1-17. http://doi. org/10.1177/0886260515586363

Piaget, J. (1994). O Juizo Moral na Crianca (E.Lenardon, trad.). São Paulo: Summus. (Trabalho original publicado em 1932).

PNUD. (2001). Relatório do Desenvolvimento Humano 2001. Fazer as Novas Tecnologias Trabalhar para o Desenvolvimento Humano. Programa Das Nações Unidas Para O Desenvolvimento.

Prensky, M. (2001). Digital Natives, Digital Immigrants. On the Horizon, 9(5), 1-6. https://doi. org/10.1108/10748120110424816

Prensky, M. (2006). Listen to the Natives. Educational Leadership, 63(4), 8-13.

Ricoy, C., Feliz, T., \& Couto, M. J. (2013). The Digital Divide among University Freshmen. Turkish Online Journal of Educational Technology - TOJET, 12(2), 262-268.

Roberto, M. S., Fidalgo, A., \& Buckingham, D. (2015). De que falamos quando falamos de infoexclusão e literacia digital? Perspetivas dos nativos digitais. Observatorio, 9(1), 043-054.

Sampieri, R. H., Collado, C. F., \& Lucio, M. del P. B. (2013). Metodologia de pesquisa (5th ed.). Porto Alegre/RS: Penso.

SANTAELLA, L. (2013). Leitor prossumidor: desafios da ubiquidade para a educação. Revista Ensino Superior Unicamp, abr-jun(9), 19-28.
Schwartz, G. (2013). Smile: You are at Play! Videogames, Education and the Morality of Icons in the Mediapolis. Significação: Revista de Cultura Audiovisual, 40(39), 231-242. https://doi.org/10.11606/issn.2316-7114. sig.2013.59958

Silva, E. P., Silva, L. C. F. S., \& Montoya, A. O. D. (2014). A educação moral: de Durkheim à Piaget. Revista Luminária, 16(2), 1-26.

Soares, I. de O. (2006). Educomunicação - o que é isto? (Vol. maio). São Paulo: Gens instituto de educação e cultura.

Srivastava, C., Dhingra, V., Bhardwaj, A., \& Srivastava, A. (2013). Morality and moral development: Traditional Hindu concepts. Indian Journal of Psychiatry, 55, 283.

Talwar, V., Gomez-Garibello, C., \& Shariff, S. (2014). Adolescents' moral evaluations and ratings of cyberbullying: The effect of veracity and intentionality behind the event. Computers in Human Behavior, 36, 122-128. https://doi.org/10.1016/j.chb.2014.03.046

Turiel, E. (1983). The development of social knowledge: morality and convention (2nd ed.). Cambridge.

Turiel, E. (2012). Moral reasoning, cultural practices, and social inequalities. Innovacion Educativa, 12(59), 17-32.

UNESCO. Transformando Nosso Mundo: A Agenda 2030 para o Desenvolvimento Sustentável (2015). Rio de Janeiro. Recuperado de http://www.unesco. org/new/pt/brasilia/post-2015-development agenda/ unesco-and-sustainable-development-goals/ sustainable-development-goals-for-education/

UNESCO. (2017). School Violence and Bullying: Global Status Report.

Valente, J. A. (1997). Informática na educação: instrucionismo x construcionismo. Manuscrito não publicado. Campinas/SP: NIED/Unicamp. Recuperado de http://www.educacaopublica.rj.gov.br/biblioteca/ tecnologia/0003.html

Valente, J. A. (2016). Integração do Pensamento Computacional no Currículo da Educação Básica: Diferentes Estratégias Usadas e Questões de Formação de Professores e Avaliação do Aluno. Revista E-Curriculum, 14, 864-897. Retrieved from http://www.redalyc.org/ pdf/766/76647706006.pdf

Recebido em: 01 de fevereiro de 2018 Aprovado em: 13 de setembro de 2020 